\title{
Article \\ Effect of Thiourea Containing Composite Additives on Nickel Electrodeposition in Ammoniacal Solution
}

\author{
Liang Yuan ${ }^{1,2}$, Jinhong Chen ${ }^{2}$, Jingxiang Zhang ${ }^{1}$ and Lingna Sun ${ }^{2, *}$ \\ 1 School of Chemistry and Environmental Engineering, Hanshan Normal University, Chaozhou 521041, China; \\ yuanliangjx@163.com (L.Y.); zhangjx@hstc.edu.cn (J.Z.) \\ 2 College of Chemistry and Environmental Engineering, Shenzhen University, Shenzhen 518060, China; \\ cjh15012653653@126.com \\ * Correspondence: lindasun1999@126.com or sunln@szu.edu.cn; Tel.: +86-0755-2653-6141
}

Citation: Yuan, L.; Chen, J.; Zhang, J.; Sun, L. Effect of Thiourea Containing Composite Additives on Nickel Electrodeposition in Ammoniacal Solution. Crystals 2022, 12, 43. https://doi.org/10.3390/cryst12010043 Academic Editors: Haichang Zhang, Maning Liu, Jing Hua, Meng Zheng, Daohai Zhang and Stefano Carli

Received: 16 November 2021 Accepted: 23 December 2021 Published: 29 December 2021

Publisher's Note: MDPI stays neutral with regard to jurisdictional claims in published maps and institutional affiliations.

Copyright: (c) 2021 by the authors. Licensee MDPI, Basel, Switzerland. This article is an open access article distributed under the terms and conditions of the Creative Commons Attribution (CC BY) license (https:// creativecommons.org/licenses/by/ $4.0 /)$.

\begin{abstract}
Composite additives have an important influence on the process of metal electrodeposition and the quality of a metal deposited layer. In this work, the additive thiourea (TU) was compounded with cetyltrimethyl ammonium chloride (CTAC), sodium dodecyl sulfate (SDS) and polyethylene glycol 20,000 (PEG20000), and their effect on the cyclic voltammetric behavior, electrochemical nucleation mechanism, crystallographic orientations and surface morphology of the nickel electrodeposition in ammoniacal solution were experimentally investigated. The results show that the introduction of composite additives resulted in a stronger cathodic polarization and increased the nucleation overpotential (NOP) values significantly, which had an important impact on forming compact and smooth nickel deposits. The chronoamperometry analysis indicated that the reduction in nickel followed the 3D progressive nucleation mechanism in the presence of composite additives at the step potential of $-1.16 \mathrm{~V}$ and $-1.18 \mathrm{~V}$. Smoother and finer nickel films were found using scanning electron microscopy (SEM) images as the composite additives were used. X-ray diffraction revealed that all nickel deposit samples had the face-centered cubic structure, and five main crystal planes were displayed by the presence of composite additives in the electrolyte. Furthermore, the diffraction peaks of (111) and (200) crystal planes were slightly shifted toward lower $2 \theta$ values when thiourea was used in combination with additive CTAC or PEG20000. These results were beneficial for understanding the mechanisms and facilitating the rational design of additives for metal nickel electrodeposition.
\end{abstract}

Keywords: nickel electrodeposition; compound additives; thiourea; ammoniacal solution

\section{Introduction}

Electrodeposited nickel films have been used widely as a matrix of composite electrochemical coatings and many other applications, such as surface engineering or materials applications, due to their excellent mechanical, anticorrosion, electrocatalytic, thermal, decorative, wear-resistance and magnetic properties [1-7]. Until now, most of the nickel films were obtained by electrodeposition in acidic electrolytes, such as sulfate, chloride, acetate and Watts-type baths [8-15]. Among these, nickel films electrodeposited from a Watts bath is the most commonly used acid-base solution system, chiefly because of low internal stress and good ductility of the final nickel deposits. However, hydrogen evolution is inevitable, which influences current efficiency, quality of the nickel deposits and harsh corrosiveness to equipment in these conventional acidic nickel-plating baths, even though various measures, such as adding additives, changing composition of solutions, $\mathrm{pH}$, temperature and substrate types, have been taken to interfere in the cathode interface process.

Nickel electrodeposition from ammonia-containing solutions has the advantages of high current efficiency, fast deposition rate, low energy consumption and slight corrosiveness to equipment, which is expected to solve the problems in the production and application of acidic nickel electrodeposition [16,17]. So far, research on metal and alloys 
electrodeposition from ammonia-containing solution, such as $\mathrm{Zn}, \mathrm{Cu}, \mathrm{Co}, \mathrm{Pd}, \mathrm{Cd}-\mathrm{Te}, \mathrm{Zn}-\mathrm{Ni}$, Co-Mo and Ni-Co, have been conducted and some have industrial applications [18-25]. Until now, there are still few studies about nickel electrodepositing from the ammoniacontaining solution, mainly because of the complexity of nickel species in ammonia solution and low current efficiency. Furthermore, although nickel electrodeposition from ammoniacontaining solutions also has the advantages mentioned above, unfavorable morphologies such as branched, spongy or mossy, as well as loose, black and brittle deposits were easily formed, which were unable to meet the product quality requirements, and its industrial applications are remarkably limited [26]. Fortunately, some measures, such as changing the electrodeposition conditions or adding single additive thiourea, have been taken to improve the deposits quality and performance in the precious study from $\mathrm{NH}_{3}-\mathrm{NH}_{4} \mathrm{Cl}_{-} \mathrm{H}_{2} \mathrm{O}$ system, and the results are quite acceptable, but there is still room for further improvement [27]. Based on that, it was assumed that adding thiourea with other organic additives, the deposits quality and performance would be modified because of their synergistic effect. Therefore, in this work, the effect of additive thiourea mixed with cationic additive cetyltrimethylammonium chloride (CTAC), anionic additive sodium dodecyl sulfate (SDS) and nonionic additive polyethylene glycol 20,000 (PEG20000) on nickel electrodeposition from $\mathrm{NH}_{3}-\mathrm{NH}_{4} \mathrm{Cl}-\mathrm{H}_{2} \mathrm{O}$ solution were studied, respectively. This research is beneficial to understand the function and mechanism of additives and can provide guidance to additive selection and compounding.

\section{Materials and Methods}

Three different types of substances, CTAC, SDS and PEG20000 purchased from Sinopharm Chemical Reagent Co., Ltd. (Shanghai, China), were selected as additives and compounded with thiourea. Their simple molecular structures are shown in Figure 1. For all experiments, the bath solution used for nickel electrodeposition was freshly prepared and was composed of $0.1 \mathrm{~mol} / \mathrm{L} \mathrm{NiCl}_{2}, 0.25 \mathrm{~mol} / \mathrm{L} \mathrm{NH}_{4} \mathrm{Cl}$ and $0.4 \mathrm{~mol} / \mathrm{L} \mathrm{NH}_{3} \cdot \mathrm{H}_{2} \mathrm{O}$. The additive content for each experiment was $0.2 \mathrm{mmol} / \mathrm{L}$ and was added to the electrolytic bath in aliquots from freshly prepared stock solution of $1 \mathrm{~mol} / \mathrm{L}$. All chemical reagents were of analytical grade and used directly without any purification. Millipore Milli-Q water (Millipore, Massachusetts Institute, Cambridge, MA, USA, USA) $(>18 \mathrm{M} \Omega / \mathrm{cm})$ was used in all the experiments. Electrochemical tests were performed on an electrochemical workstation (Shanghai Chenhua Instrument CHI 660E, Shanghai, China) by a conventional three electrode glass cell at $25^{\circ} \mathrm{C}$. A glassy carbon disk (Aida Technology Co., Ltd, Tianjin, China) with a diameter of $3 \mathrm{~mm}$ was used as the working electrode. Before use, the working electrode was ground using a fine emery paper, then polished on a polishing cloth with $0.5 \mu \mathrm{m}$ $\mathrm{Al}_{2} \mathrm{O}_{3}$ powder and finally washed thoroughly several times with acetone and alcohol. A saturated calomel electrode (SCE) (model SCE 232, Yueci Electronic Technology Co., Ltd., Shanghai, China) mounted inside a Luggin capillary was used as the reference electrode, so all potentials were referred to this electrode. The reference electrode was placed as close as possible to the surface of the working electrode via the Luggin capillary so as the $\mathrm{Ohm}$ drop could be neglected. A platinum sheet of $10 \mathrm{~mm} \times 10 \mathrm{~mm}$ was used as the auxiliary electrode. Prior to each electrochemical measurement, high purity nitrogen was bubbled into the bath for $10 \mathrm{~min}$ to sparge out dissolved oxygen and maintain an inert atmosphere before electrochemical tests. Cyclic voltammetry tests were carried out from the open circuit potential with a scan rate of $50 \mathrm{mV} / \mathrm{s}$. The stepped potentials for the chronoamperometric measurements were selected from the corresponding CV curves to sufficiently initiate the nucleation and growth of nickel crystals. All the electrochemical tests were conducted at least three times to obtain results with good agreement.

X-ray diffraction analysis was carried out on an X-ray diffractometer (model Rigaku $\mathrm{D} / \mathrm{max} 2550$, Nippon Science Corporation, Japan) with monochromatized $\mathrm{Cu}-\mathrm{K} \alpha$ radiation $(\lambda=1.5406 \AA)$, working at $30 \mathrm{~mA}$ and $40 \mathrm{kV}$ to determine the crystal structure and phase composition of the final nickel deposits. The diffractograms of the nickel deposits were obtained in the $2 \theta$ range of $20-100^{\circ}$ using a $0.02^{\circ}$ step and an acquisition time of $2 \mathrm{~s} / \mathrm{step}$. 
The morphologies of the nickel deposits were examined using a scanning electron microscope (model XL30-ESEM, Philips, The Netherlands). The samples used for the XRD and SEM tests were prepared on a pure titanium plate substrate by a small scale electrolysis in a plexiglass cell at $25^{\circ} \mathrm{C}$ under a cathodic current density of $40 \mathrm{~mA} / \mathrm{cm}^{2}$ for $120 \mathrm{~min}$.

TU<smiles>NC(N)=S</smiles>

PEG 20000

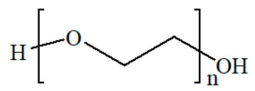

SDS

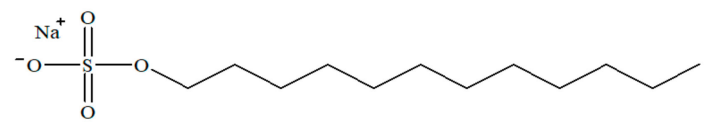

CTAC

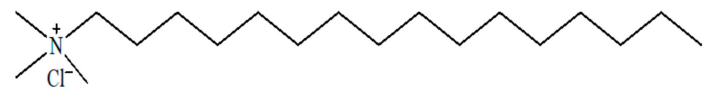

Figure 1. Simple molecular structure of additives.

\section{Results and Discussion}

\subsection{Cyclic Voltammetric Behavior}

Figure 2 illustrates the cyclic voltammetry curves for nickel electrodeposition on a glassy carbon electrode in the presence of various additives, and the arrows represent the scanning direction of cyclic voltammetry. A typical current hysteresis loop appeared in the negative scan direction at the cathodic parts of the curves, which indicate that a nucleation/growth process was involved and an overpotential was required in the nickel electrodeposition process in the presence of additives. Usually, the potential difference between the nucleation potential $\left(E_{\mathrm{nu}}\right)$ and the crossover potential $\left(E_{\mathrm{co}}\right)$ is defined as nucleation overpotential (NOP), which is regarded as a measure of cathode polarization, and higher NOP value means a stronger polarization [28]. The values of $E_{\mathrm{co}}, E_{\mathrm{nu}}$ and NOP of nickel electrodeposition with composite additives are listed in Table 1.

Table 1. Effect of additives on the cross overpotential $\left(E_{\mathrm{co}}\right)$, nucleation potential $\left(E_{\mathrm{nu}}\right)$ and nucleation overpotential (NOP) of nickel electrodeposition.

\begin{tabular}{cccc}
\hline $\begin{array}{c}\text { Additive } \\
\text { Composition }\end{array}$ & $\begin{array}{c}-\boldsymbol{E}_{\mathbf{c o}} \\
\mathbf{( m \mathbf { ) }}\end{array}$ & $\begin{array}{c}-\boldsymbol{E}_{\mathbf{n u}} \\
\mathbf{( m \mathbf { V } )}\end{array}$ & $\begin{array}{c}\text { NOP } \\
(\mathbf{m V})\end{array}$ \\
\hline TU & 995 & 1163 & 168 \\
TU + CTAC & 986 & 1181 & 195 \\
TU + SDS & 1002 & 1186 & 184 \\
TU + PEG20000 & 994 & 1182 & 188 \\
\hline
\end{tabular}

Introduction of composite additives shifted the $E_{\mathrm{nu}}$ and cathodic peak potential in the negative direction, resulting in stronger cathodic polarization. Compared with single additive thiourea, the composite additives increased the nucleation overpotentials more significantly, especially when thiourea was compounded with CTAC. This may be related to the co-adsorption and strong synergetic effect of the two additives, which are much more likely to transfer to the cathode interface under the application of electric field and further adsorb on the active sites of the electrode. Furthermore, the adsorbed additives hinder the discharge reduction in nickel ammonia complex ions and inhibit the process of nickel electrodeposition. Two anodic peaks with small peak currents appeared on the anode part of cyclic voltammetry curves when the composite additives were introduced. Anodic peak with positive potential was mainly attributed to the oxidation of thiourea and the other one was the dissolution of nickel deposits or the formation of nickel hydroxide. 


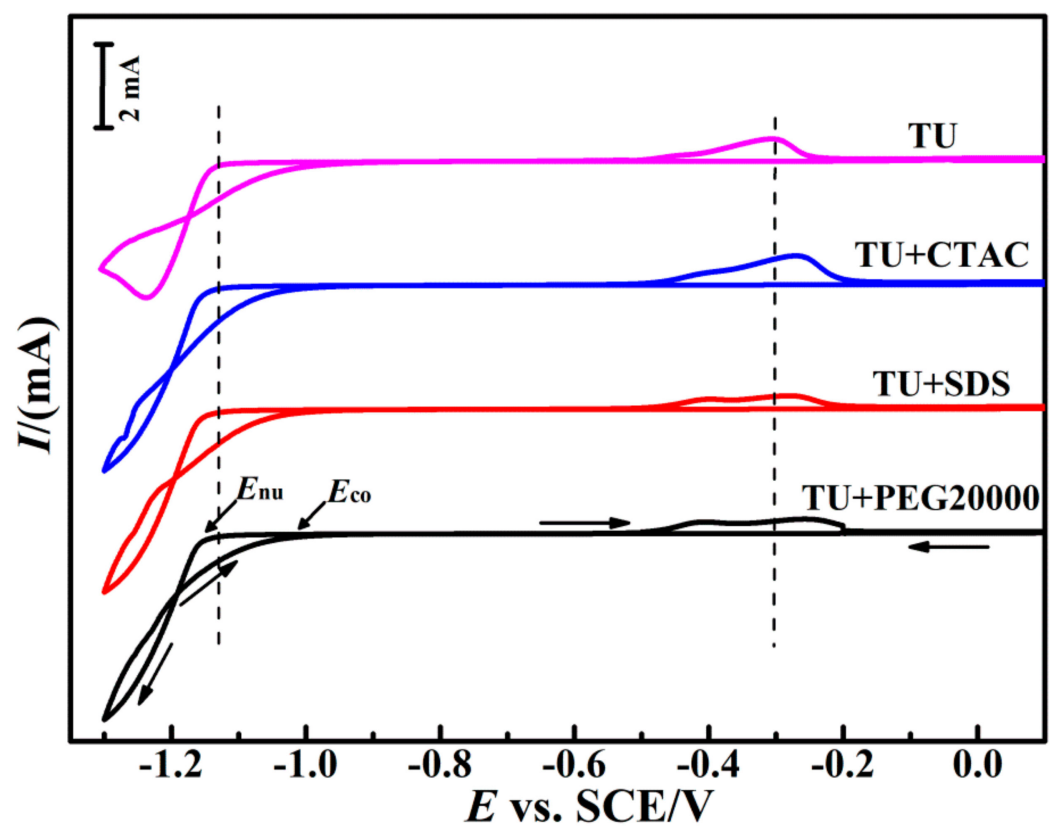

Figure 2. Cyclic voltammetry curves for nickel electrodeposition from ammoniacal solutions by containing composite additives.

\subsection{Nucleation and Growth Mechanism}

The effect of composite additives on a nickel electrodeposition nucleation mechanism was investigated by chronoamperometry technique, and the potentiostatic current-time transients curves at different potentials are presented in Figure 3. The current peaked in a short time due to the formation and growth of crystal nuclei, then the current decreased gradually from the electron transfer and tended to be flat state at last because of the growth of the nickel nuclei. This shows the typical characteristic of a diffusion controlled electrochemical nucleation process with three-dimensional growth of nuclei and can be characterized by the Cottrell equation in Equation (1) [29]:

$$
i=\frac{n F A D^{1 / 2} c_{0}}{\pi^{1 / 2} t^{1 / 2}}
$$

where $i$ is the current passing through the electrolyte, $n$ the number of electrons involved, $F$ the Faraday constant, $A$ the working area of electrode, $D$ the diffusion coefficient, $c_{0}$ the concentration of species in the bulk and $t$ the time. The diffusion coefficient is an important kinetics parameter which is used to estimate the effect of additives on nickel electrodeposition and can be determined by the slope of chronoamperograms in $i$ versus $t^{-1 / 2}$ coordinates according to the Cottrell equation. Table 2 shows that when thiourea was compounded with SDS and CTAC, the diffusion coefficient decreased at different potentials, especially in the presence of SDS. This results largely from the viscosity of the solution by the introduction of SDS and CTAC, which further reduced the mass transport of nickel complex ions. However, the diffusion coefficient increased when thiourea was compounded with PEG20000, which may be related to PEG20000 with the function of improving dispersibility of the electrolyte. Comparison of some other parameters such as the maximum transient current value $\left(I_{\max }\right)$ and the time to reach the maximum transient current value $\left(t_{\max }\right)$ are also shown in Figure 3. When the potential was more negative, the value of $I_{\max }$ was higher and the value of $t_{\max }$ was smaller. 

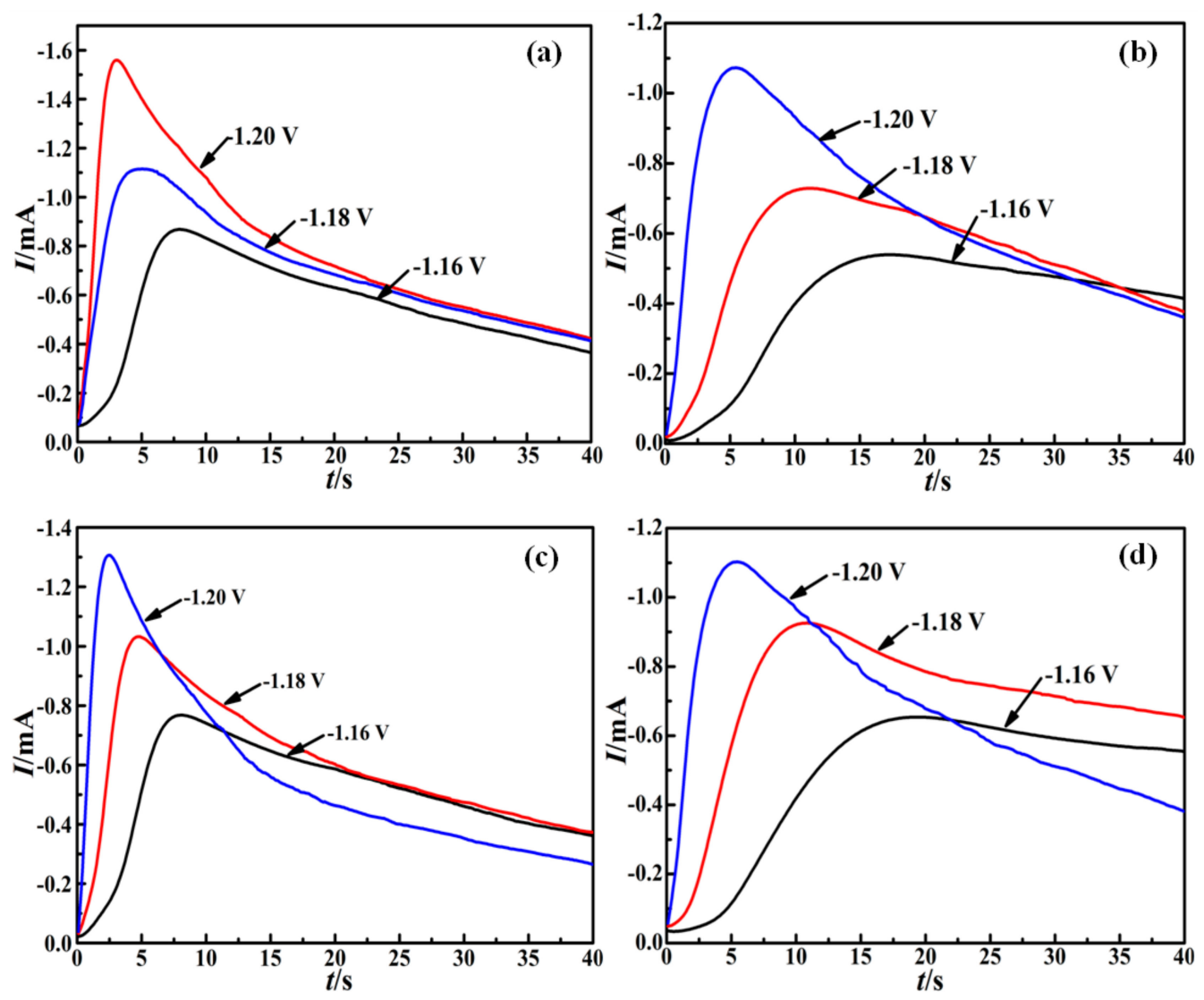

Figure 3. Typical current-time transient for nickel electrodeposition in the presence of additives at different potentials. (a) TU, (b) TU+ CTAC, (c) TU+ SDS, (d) TU + PEG20000.

To further understand the electrochemical nucleation process mechanism in great detail, the classical limiting three-dimensional nucleation model proposed by Scharifker and Hills was employed and it was confirmed that the electrode reaction was controlled by diffusion step in the previous work [30-32]. This is the most rational and widely used model to analyze the current transients for the nucleation/growth mechanism at the initial stages for metal electrodeposition. In this model, the nucleation/growth mechanism is classified as 3D instantaneous nucleation and 3D progressive nucleation, and the general equations are:

For 3D instantaneous nucleation [33]:

$$
I=n F D^{1 / 2} c\left[1-\exp \left(-N_{0} \pi k^{\prime} D t\right)\right] /(\pi t)^{1 / 2}
$$

For 3D progressive nucleation [33]:

$$
I=n F D^{1 / 2} c\left[1-\exp \left(-A N_{0} \pi k D t^{2} / 2\right)\right] /(\pi t)^{1 / 2}
$$

where $n$ is the number of electrons transferred, $F$ the Faraday constant, $D$ the diffusion coefficient, $c$ the bulk concentration, $A$ the nucleation rate constant, $N_{0}$ the number of nuclei density, $k$ and $k^{\prime}$ the constant decided by the experiment. For instantaneous nucleation, all the nuclei occurred simultaneously, and the growth occurred rapidly, but the overall number of effectively formed active nucleation sites was small. On the other hand, the nuclei were created at a large number of active nucleation sites and generated continuously with slow growth rate for progressive nucleation. After a series of mathematical transfor- 
mation, dimensionless equations of instantaneous nucleation and progressive nucleation were derived by normalizing $\left(I / I_{\max }\right)^{2} \sim t / t_{\max }$ as shown in Equations (4) and (5).

$$
\begin{aligned}
& \left(\frac{I}{I_{m}}\right)^{2}=\frac{1.9542}{t / t_{m}}\left\{1-\exp \left[-1.2564\left(\frac{t}{t_{m}}\right)\right]\right\}^{2} \\
& \left(\frac{I}{I_{m}}\right)^{2}=\frac{1.2254}{t / t_{m}}\left\{1-\exp \left[-2.3367\left(\frac{t}{t_{m}}\right)^{2}\right]\right\}^{2}
\end{aligned}
$$

The value of $I_{\max }$ at $t=t_{\max }$ can be easily obtained from the current-time transient curves and the fitted $\left(I / I_{\max }\right)^{2} \sim t / t_{\max }$ were compared to the theoretical dimensionless curve model derived for two limiting nucleation mechanism.

Figure 4 shows that the composite additives did not change the theoretical progressive nucleation mechanism at the step potential of $-1.16 \mathrm{~V}$ and $-1.18 \mathrm{~V}$ when compared to single additive thiourea. However, the nucleation mode was ambiguous between instantaneous nucleation and continuous nucleation at step potential of $-1.20 \mathrm{~V}$ when thiourea was compounded with CTAC or PEG20000. In addition, the nucleation mode of nickel agreed well with the continuous nucleation mechanism when thiourea and SDS were introduced to the bath at the same time.
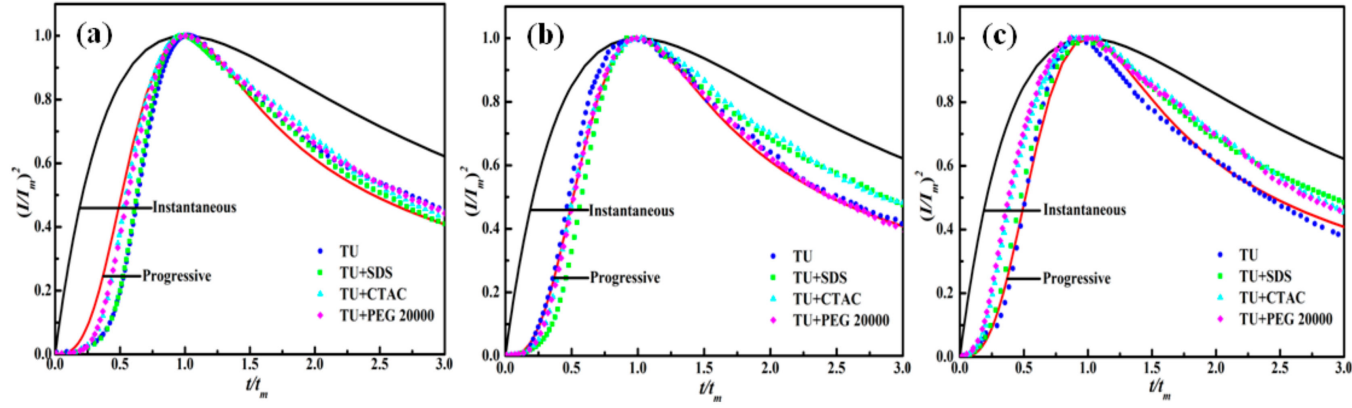

Figure 4. Corresponding Scharifker-Hills' models for nickel electrodeposition at different potentials. (a) $-1.16 \mathrm{~V},(\mathbf{b})-1.18 \mathrm{~V},(\mathbf{c})-1.20 \mathrm{~V}$.

Table 2. Maximum transient current, time to reach and the diffusion coefficient for different potentials

\begin{tabular}{|c|c|c|c|c|c|}
\hline $\begin{array}{c}\text { Additive } \\
\text { Composition }\end{array}$ & $\begin{array}{l}E \\
\mathrm{~V}\end{array}$ & $\begin{array}{c}t_{m} \\
\mathrm{~s}\end{array}$ & $\underset{\mathrm{mA} / \mathrm{cm}^{2}}{I_{m}}$ & $\begin{array}{c}I_{m}^{2} t_{m} \\
\mathrm{~mA}^{2} /\left(\mathrm{cm}^{4} \cdot \mathrm{s}\right)\end{array}$ & $\begin{array}{l}10^{9} \mathrm{D} \\
\mathrm{cm}^{2} / \mathrm{s}\end{array}$ \\
\hline \multirow{3}{*}{ TU } & -1.16 & 7.8 & 0.87 & 5.90 & 1.99 \\
\hline & -1.18 & 5.1 & 1.11 & 6.28 & 2.12 \\
\hline & -1.20 & 3.2 & 1.56 & 7.79 & 2.63 \\
\hline \multirow{3}{*}{$\mathrm{TU}+\mathrm{CTAC}$} & -1.16 & 17.6 & 0.54 & 5.13 & 1.73 \\
\hline & -1.18 & 11.1 & 0.73 & 5.92 & 2.00 \\
\hline & -1.20 & 5.5 & 1.07 & 6.30 & 2.12 \\
\hline \multirow{3}{*}{$\mathrm{TU}+\mathrm{SDS}$} & -1.16 & 8.2 & 0.77 & 4.86 & 1.64 \\
\hline & -1.18 & 4.8 & 1.03 & 5.09 & 1.72 \\
\hline & -1.20 & 2.6 & 1.31 & 4.46 & 1.50 \\
\hline \multirow{3}{*}{ TU + PEG 20000} & -1.16 & 19.3 & 0.65 & 8.15 & 2.75 \\
\hline & -1.18 & 10.9 & 0.93 & 9.43 & 3.18 \\
\hline & -1.20 & 5.8 & 1.10 & 7.02 & 2.73 \\
\hline
\end{tabular}
and composite additives.

When the value of $t / t_{\max }$ was greater than 1 , the experimental result fitted well with the theoretical curves and deviated from the theoretical trend because of the charging effect of the double layer and hydrogen evolution reaction on the electrode surface [19]. 


\subsection{Deposit Morphology}

The additives played a most important role in forming compact and smooth nickel deposits from ammoniacal solution. The effect of composite additives on nickel deposit morphology at microscopic levels was examined by using SEM analysis techniques. As shown in Figure 5a, the spherical nickel particles were relatively large only in the presence of thiourea with non-uniform and loose structure. However, the introduction of composite additives into the baths resulted in a denser and finer grain size nickel deposit in general. When thiourea was compounded with additives SDS or PEG20000, the nickel deposited layer still kept spherical and granular morphology, but some morphological defects appeared, such as porosity (in Figure 5e), particles agglomeration (in Figure 5h) and nodulation (in Figure 5g). In addition, it should be noted that the introduction of CTAC to the thiourea containing electrolyte results in entirely different nickel deposit structure. The nickel film comprised needle shaped particles rather than spherical particles (in Figure 5d). This result may be attributed to the adsorption of the composite additives on the surface of cathodic electrode. In the ammonia electrolyte, the $\mathrm{C}=\mathrm{S}$ bond in thiourea molecule is relatively easy to break to form $\mathrm{S}^{2-}$, which can react with cationic additive CTAC further and form new $\mathrm{S}$ containing compounds [34]. This compound would be strongly adsorbed on the active sites of the electrode surface and hinder the discharge reaction. These results can also be reflected from NOP value in Table 1, which has the largest NOP value.

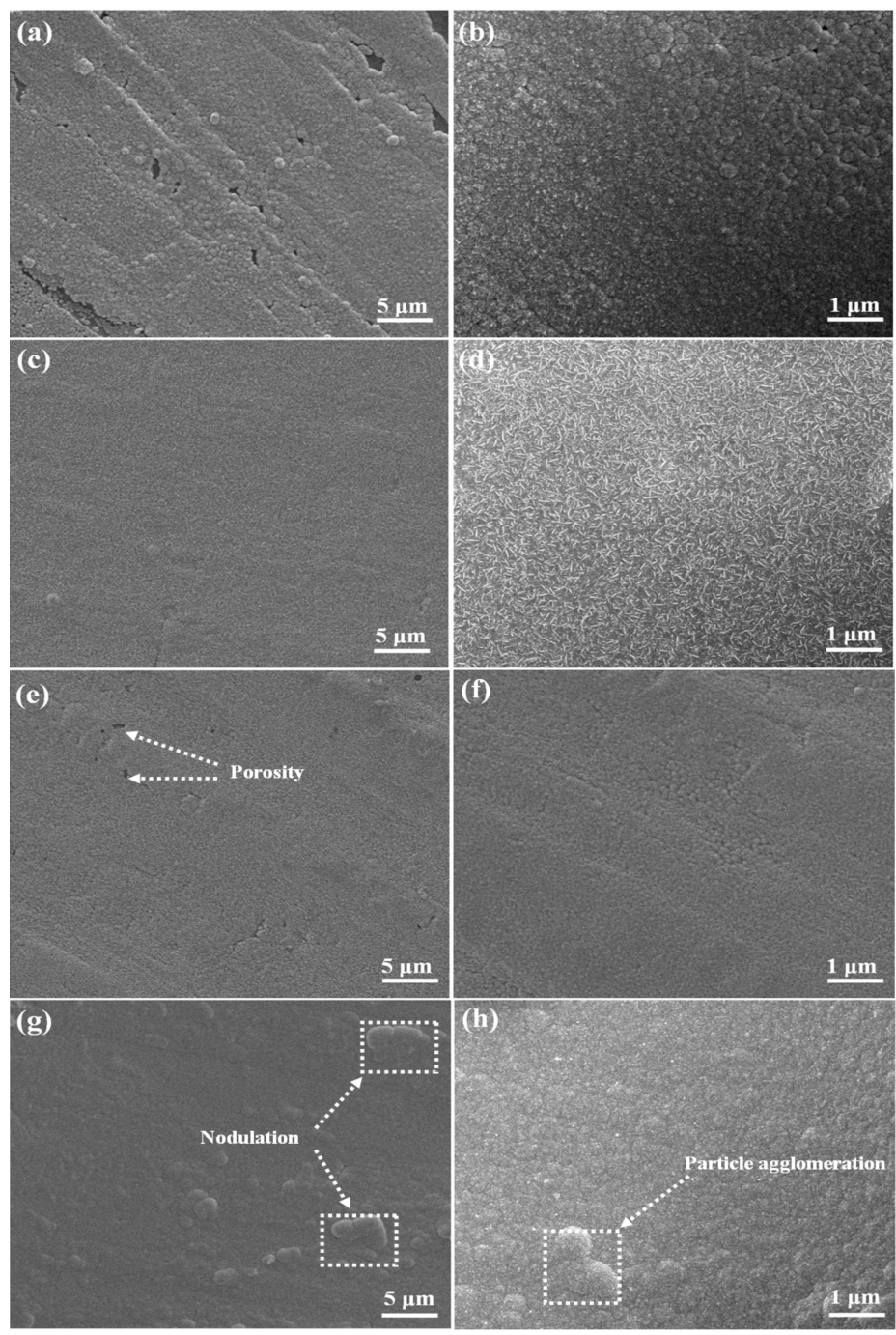

Figure 5. Scanning electron micrographs of nickel deposits with composite additives. (a,b) TU, (c,d) TU+ CTAC, (e,f) TU+ SDS, (g,h) TU + PEG20000. 


\subsection{Crystallographic Orientations}

X-ray diffraction was used to further characterize the orientations of nickel deposit samples obtained from different additive-containing baths and the diffraction patterns are shown in Figure 6. Within the diffraction angle from $20^{\circ}$ to $100^{\circ}$, all nickel deposits display typical diffraction peaks at $2 \theta=44.6^{\circ}, 51.9^{\circ}, 76.4^{\circ}, 92.8^{\circ}$ and $98.6^{\circ}$, which correspond to (111), (200), (220), (311) and (222) crystallographic planes of Ni (JCPDS: 87-0712) with face-centered cubic structure. Obviously, the crystal plane (111) has the highest diffraction intensity among the five nickel crystal planes whether or not thiourea was used in combination with other additives. However, the introduction of composite additives weakened the intensity of the diffraction peak of the (111) crystal plane, especially when thiourea was compounded with CTAC. The diffraction peaks of (111) and (200) crystal planes were slightly shifted toward lower $2 \theta$ values when thiourea was used in combination with additive CTAC or PEG20000. This slight shift of diffraction peaks may result from the changes of unit cell parameters and crystal plane spacing by the addition of composite additives.

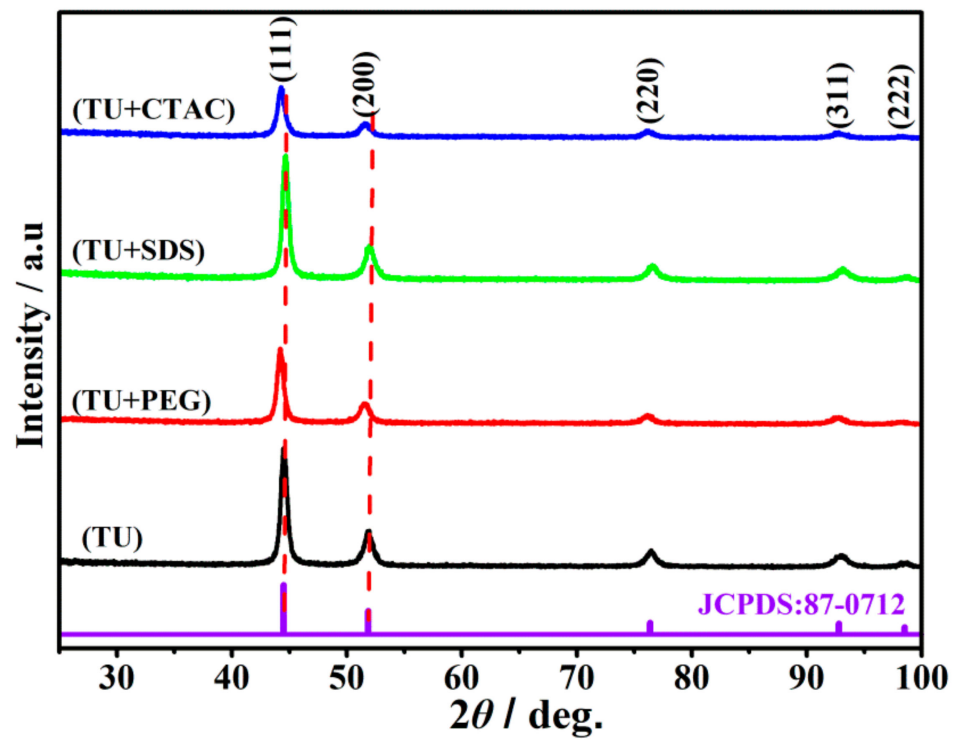

Figure 6. XRD patterns of nickel deposit in the presence of composite additives.

\section{Conclusions}

In this study, the effect of thiourea and thiourea containing composite additives on nickel electrodeposition from ammoniacal solution was investigated. It can be concluded that composite additives had an important influence on the cyclic voltammetric behavior, nickel nucleation mechanism and surface morphology.

(1) The introduction of composite additives resulted in a stronger cathodic polarization and increased the nucleation overpotential significantly.

(2) The reduction in nickel followed the 3D progressive nucleation mechanism in the presence of composite additives at the step potential of $-1.16 \mathrm{~V}$ and $-1.18 \mathrm{~V}$ but became ambiguous when thiourea was used in combination with CTAC or PEG20000 at the potential of $-1.20 \mathrm{~V}$.

(3) The composite additives had an effect on forming compact and smooth nickel deposits. The introduction of CTAC to the thiourea containing electrolyte resulted in nickel particles changing from needle-like to spherical.

(4) All nickel deposits had the face-centered cubic structure. The diffraction peaks of (111) and (200) crystal planes were slightly shifted toward lower $2 \theta$ values when thiourea was used in combination with additive CTAC or PEG20000. 
Author Contributions: Conceptualization, L.S. and J.Z.; methodology, L.Y.; software, L.Y.; validation, J.C., L.S. and J.Z.; formal analysis, L.Y.; investigation, L.Y.; resources, L.S. and J.Z.; data curation, L.Y. and J.C.; writing—original draft preparation, L.Y.; writing—review and editing, L.Y. and L.S.; visualization, L.Y. and L.S.; supervision, L.S. and J.Z.; project administration, L.S.; funding acquisition, L.S. All authors have read and agreed to the published version of the manuscript.

Funding: This work was financially supported by the Shenzhen Natural Science Fund (the Stable Support Plan Program, grant No. 20200813081943001) and the Guangdong Basic and Applied Basic Research Foundation, China (Grant No. 2021A1515010241, 2021A1515010142).

Institutional Review Board Statement: Not applicable.

Informed Consent Statement: Informed consent was obtained from all subjects involved in the study.

Data Availability Statement: The data presented in this study are available on request from the corresponding author.

Acknowledgments: The authors express their thanks to the people helping with this work and acknowledge the valuable suggestions from the peer reviewers.

Conflicts of Interest: The authors declare no conflict of interest.

\section{References}

1. Tang, Y.P.; Cao, H.Z.; Zheng, G.Q.; Hou, G.Y.; Wu, L.K. Electrodeposition of Bright Nickel from Liquid Ammonia Solution Containing Chloride. J. Electrochem. Soc. 2016, 163, D829-D835. [CrossRef]

2. Mohanty, U.S.; Tripathy, B.C.; Das, S.C.; Singh, P.; Misra, V.N. Effect of sodium lauryl sulphate on nickel electrowinning from acidic sulphate solutions. Hydrometallurgy 2009, 100, 60-64. [CrossRef]

3. Cheong, W.J.; Luan, B.L.; Shoesmith, D.W. The effects of stabilizers on the bath stability of electroless Ni deposition and the deposit. Appl. Surf. Sci. 2004, 229, 282-300. [CrossRef]

4. Lin, K.-L.; Hwang, J.-W. Effect of thiourea and lead acetate on the deposition of electroless nickel. Mater. Chem. Phys. 2002, 76, 204-211. [CrossRef]

5. Tseluikin, V.N.; Vasilenko, E.A. Electrodeposition and properties of composite coatings based on nickel. Russ. J. Appl. Chem. 2011, 84, 2005-2007. [CrossRef]

6. Gyawali, G.; Joshi, B.; Tripathi, K.; Lee, S.W. Effect of ultrasonic nanocrystal surface modification on properties of electrodeposited $\mathrm{Ni}$ and $\mathrm{Ni}$-SiC composite coatings. J. Mater. Eng. Perform. 2017, 26, 4462-4469. [CrossRef]

7. Lanzutti, A.; Lekka, M.; de Leitenburg, C.; Fedrizzi, L. Effect of pulse current on wear behavior of Ni matrix micro-and nano-SiC composite coatings at room and elevated temperature. Tribol. Int. 2019, 132, 50-61. [CrossRef]

8. Antihovich, I.V. Electrodeposition of nickel and composite nickel-fullerenol coatings from low-temperature sulphate-chlorideisobutyrate electrolyte. Procedia Chem. 2014, 10, 373-377. [CrossRef]

9. Sharma, P.; Bhale, J.; Mishra, A.; Malviya, P. Synthesis and X-ray diffraction study of some nickel(II) complexes of urea and thiourea. J. Phys. 2014, 534, 012044. [CrossRef]

10. Zhu, Y.-L.; Katayama, Y.; Miura, T. Effects of acetone and thiourea on electrodeposition of Ni from a hydrophobic ionic liquid. Electrochimica Acta 2012, 85, 622-627. [CrossRef]

11. Jing, L.U.; Yang, Q.H.; Zhang, Z. Effects of additives on nickel electrowinning from sulfate system. Trans. Nonferrous Met. Soc. China 2010, 20, 97-101.

12. Jin, Y.; Hongying, Y.U.; Yang, D.; Sun, D. Effects of complexing agents on acidic electroless nickel deposition. Rare Met. 2010, 29, 401-406. [CrossRef]

13. Rudnik, E.; Wojnicki, M.; Włoch, G. Effect of gluconate addition on the electrodeposition of nickel from acidic baths. Surf. Coatings Technol. 2012, 207, 375-388. [CrossRef]

14. Srinivasan, R.; Bapu, G.N.K.R. Effect of additives on electrodeposition of nickel from acetate bath: Cyclic voltammetric study. Trans. Inst. Met. Finish. 2013, 91, 52-56. [CrossRef]

15. Loto, C.A.; Loto, R.T. Effect of dextrin and thiourea additives on the Zinc electroplated mild steel in acid chloride solution. Int. J. Electrochem. Sci. 2013, 8, 12434-12450.

16. Cao, H.; Di, Y.; Zhu, S.; Li, D.; Zheng, G. Preparation, characterization, and electrochemical studies of sulfur-bearing nickel in an ammoniacal electrolyte: The influence of thiourea. J. Solid State Electrochem. 2012, 16, 3115-3122. [CrossRef]

17. Borikar, D.K.; Umare, S.S.; Viswanath, S.G. Electrowinning of nickel from ammonical sulphate bath and effect of aceton on morphology of nickel deposit and its correlation with kinetic parameters. Metalurgija 2006, 45, 3-8.

18. Jović, V.D.; Jović, B.M.; Pavlović, M.G. Morphology and composition of Ni-Co alloy powders electrodeposited from ammoniacal electrolyte. J. Solid State Electrochem. 2006, 10, 959-966. [CrossRef]

19. Grujicic, D.; Pesic, B. Reaction and nucleation mechanisms of copper electrodeposition from ammoniacal solutions on vitreous carbon. Electrochimica Acta 2005, 50, 4426-4443. [CrossRef] 
20. Grujicic, D.; Pesic, B. Electrochemical and AFM study of cobalt nucleation mechanisms on glassy carbon from ammonium sulfate solutions. Electrochimica Acta 2004, 49, 4719-4732. [CrossRef]

21. Burlyaev, D.V.; Tinaeva, A.E.; Tinaeva, K.E. Electrodeposition of Zinc-Nickel Coatings from Glycine-Containing AmmoniumChloride Electrolyte. Prot. Met. Phys. Chem. Surfaces 2020, 56, 552-559. [CrossRef]

22. Mech, K.; Żabiński, P.; Kowalik, R.; Tokarski, T.; Fitzner, K. Electrodeposition of Co-Pd alloys from ammonia solutions and their catalytic activity for hydrogen evolution reaction. J. Appl. Electrochem. 2014, 44, 97-103. [CrossRef]

23. Mech, K.; Żabiński, P.; Kowalik, R.; Fitzner, K. Analysis of Co-Pd alloys deposition from electrolytes based on [Co(NH3)6]3+ and [Pd(NH3)4]2+ complexes. Electrochimica Acta 2013, 104, 468-473. [CrossRef]

24. Kuznetsov, V.V.; Bondarenko, Z.V.; Pshenichkina, T.V.; Morozova, N.V.; Kudryavtsev, V.N. Electrodeposition of a cobaltmolybdenum alloy from an ammonia-citrate electrolyte. Russ. J. Electrochem. 2007, 43, 349-354. [CrossRef]

25. Dergacheva, M.B.; Statsyuk, V.N.; Fogel, L.A. Electrodeposition of CdTe from ammonia-chloride buffer electrolytes. J. Electroanal. Chem. 2005, 579, 43-49. [CrossRef]

26. Yuan, L.; Hu, J.G.; Ding, Z.Y.; Liu, Z.J. Electrochemical deposition of bright nickel on titanium matrix from ammoniacal solution in the presence of thiourea. Int. J. Electrochem. Sci. 2017, 12, 7312-7325. [CrossRef]

27. Yuan, L.; Hu, J.G.; Chang, G.; Tang, J.; Ji, X.B.; Liu, Z.J. The Contribution of Heteroatoms in Amide Derivatives with an Identical Structure on Nickel Electrodeposits. J. Electrochem. Soc. 2019, 166, D381-D388. [CrossRef]

28. Zhang, Q.B.; Hua, Y.X. Effects of [HMIM]HSO4 and [OMIM]HSO4 on the electrodeposition of zinc from sulfate electrolytes. J. Appl. Electrochem. 2009, 39, 1185-1192. [CrossRef]

29. Rooij, D. Electrochemical methods: Fundamentals and applications. J. Chem. Educ. 2003, 50, A25-A26. [CrossRef]

30. Scharifker, B.; Hills, G. Theoretical and experimental studies of multiple nucleation. Electrochimica Acta 1983, 28, 879-889. [CrossRef]

31. Scharifker, B.R.; Mostany, J.; Palomar, P.M. On the Theory of the Potentiostatic Current Transient for Diffusion-Controlled Three-Dimensional Electrocrystallization Processes. J. Electrochem. Soc. 1999, 146, 1005-1012. [CrossRef]

32. Yuan, L.; Ding, Z.-Y.; Liu, S.-J.; He, Y.-N. Cathodic process of nickel electrodeposition from ammonia-ammonium chloride solutions. Rare Met. 2017, 1-6. [CrossRef]

33. Song, Y.; Tang, J.; Hu, J.; Liu, S.; Fu, Y.; Ji, X. Insights into electrodeposition process of nickel from ammonium chloride media with speciation analysis and in situ synchrotron radiation X-ray imaging. Electrochimica Acta 2016, 210, 812-820. [CrossRef]

34. Zhao, J.M.; Liu, H.X.; Di, W. The inhibition synergistic effect between imidazoline derivative and thiourea. Electrochemistry 2004, 10, 440-445. 